154 Network Science 1 (2): 154-169, 2013. (C) Cambridge University Press 2013. The online version of this article is published within an Open Access environment subject to the conditions of the Creative Commons Attribution-NonCommercial-ShareAlike licence <http://creativecommons.org/licenses/by-nc-sa/ $3.0 />$. The written permission of Cambridge University Press must be obtained for commercial re-use. doi:10.1017/nws.2013.7

\title{
The decomposed affiliation exposure model: $A$ network approach to segregating peer influences from crowds and organized sports
}

\author{
KA Y O FUJIMOTO \\ Division of Health Promotion and Behavioral Sciences, School of Public Health, University of Texas \\ Health Science Center at Houston, Houston, TX, USA \\ (e-mail: Kayo.Fujimoto@uth.tmc.edu) \\ PENG WANG \\ Melbourne School of Psychological Sciences, The University of Melbourne, Australia \\ THOMAS W. VALENTE \\ Institute for Prevention Research, Department of Preventive Medicine, Keck School of Medicine, \\ University of Southern California, Los Angeles, CA, USA
}

\begin{abstract}
Self-identification with peer crowds (jocks, popular kids, druggies, etc.) has an important influence on adolescent substance use behavior. However, little is known about the impact of the shared nature of crowd identification on different stages of adolescent drinking behavior, or the way crowd identification interacts with participation in school-sponsored sports activities. This study examines drinking influences from (1) peers with shared crowd identities, and (2) peers who jointly participate in organized sports at their school (activity members). This study introduces a new network analytic approach that can disentangle the effects of crowd identification and sports participation on individual behavior. Using survey data from adolescents in five high schools in a predominantly Hispanic/Latino district $(\mathrm{N}=1,707)$, this paper examines the association between social influences and each stage of drinking behavior (intention to drink, lifetime, past-month, and binge drinking) by conducting an ordinal regression analysis. The results show that both shared identities and joint participation were associated with all stages of drinking, controlling for friends' influence. Additionally, shared identification overlapped with joint participation was associated with more frequent drinking. Related policy implications are discussed.
\end{abstract}

Keywords: adolescent alcohol use, affiliation exposure model, peer influence, two-mode affiliation network, multiplex networks, organized sports participation, crowd identification

\section{Introduction}

The adolescent peer system plays a prominent role in personal and social development by influencing norms and behaviors. One component of this peer system is the group or crowd which is an amorphous collection of individuals who share an identity or activity (Brown et al., 1986; Brown \& Lohr, 1987). Groups and crowds extend beyond small interaction-based groups of peers formed primarily on friendship. Classical social psychological theories recognized that adolescents attached importance to these crowds based on status hierarchies or the popularity of 
one's crowd (Brown \& Lohr, 1987; Coleman, 1961). Other theories focused on the role of peer groups on identity development or identity evaluation (Coleman, 1980; Erikson, 1968; Newman \& Newman, 1976), age-varying levels of peer conformity dispositions (Coleman, 1974; Costanzo \& Shaw, 1966; Gavin \& Furman, 1989), or development and maintenance of self-esteem (Brown \& Lohr, 1987; Coleman, 1961). There is often consensus among adolescents on the stereotypic traits and behavioral patterns of crowds indicated by their primary attitudes or activities, often reflected by their labels such as "jocks," "brains," "loners," "druggies," and so on (Brown, 1990). Members of crowds may or may not have direct interaction with each other (Sussman et al., 2007).

Participation in school-sponsored activities also provides adolescents with the opportunity to interact with peers and can serve as a context for adolescents to express and refine their crowd identity (Eccles et al., 2003; Barber et al., 2005; Eccles \& Barber, 1999), and absorb the shared values and norms associated with the group (Eccles \& Barber, 1999). The norms of a particular crowd may or may not coincide with those of the related school-sponsored activities. Furthermore, adolescents may not agree on the norms of a particular crowd. This could be due to variation in adolescents' ability to perceive the adolescent peer system accurately, to variation in ethnic backgrounds, or to other features that impact an adolescent's understanding of the adolescent peer system. For example, minority students in multi-ethnic social environments might perceive the adolescent peer system differently than non-minority students' (Brown et al., 1990).

Many studies have shown that adolescent self-identification with certain crowds' serves as a predictor of substance use and other problem behaviors (Jessor, 1984; La Greca et al., 2001; Miller et al., 2003; Mosbach \& Leventhal, 1988; Sussman et al., 2000; Sussman et al., 1999; Sussman et al., 2004; Verkooijen et al., 2007). For example, "Deviants" (including stoner, tough, heavy metaller, druggie, or burnout) were the most likely crowd group to engage in substance use or risk-taking behaviors (teen dating/participation in sexual behavior and involvement in violent situations) (Sussman et al., 2007). In another study, Druggies and Toughs were reported to be equivalent crowd stereotypes in most high schools (Brown et al., 1990). Taking the above studies into account, certain crowds have fairly universal stereotypes that relate in some way to substance use.

Participation in school-sponsored organized activities has been shown to be both a risk and protective factor for adolescent substance use or problem behavior. For example, Mahoney and colleagues (Mahoney \& Cairns, 1997; Mahoney, 2000) noted that peer involvement in extracurricular activities was associated with a lower risk of early dropout or antisocial behavior for high-risk youth. Other studies report that male and female athletes were less likely to have ever smoked regularly (Melnick et al., 2001), and male sports participants were less likely than non-participants to report cigarette smoking, cocaine, and other illegal drug use (Pate et al., 2000).

However, this association does not seem to apply to alcohol use (Darling, 2005; Eccles \& Barber, 1999). For example, participation in extracurricular sports activities was linked to an increase in drinking alcohol (Eccles \& Barber, 1999), and was associated with having a higher proportion of friends who drank alcohol (Eccles et al., 2003). Additionally, sports participation (especially team sports participation) during adolescence has been shown to increase the frequency of alcohol intoxication 
during late adolescent and early adult years (Wichstrøm \& Wichstrøm, 2009). These results indicate that peer group affiliation through participation in extracurricular activities influences adolescent drinking behavior.

By combining crowd identification and activity participation, Millers and colleagues (2005) distinguished the objective athlete (what adolescents actually do) from the subjective athlete (what adolescents perceive themselves to be). By operationalizing two measures of adolescents' athletic involvement, objective experience (frequency of athletic activity) and subjective experience (jock identity), they demonstrated different impacts of objective and subjective athletic involvement on adolescent sexual behavior, such that athletic activity was associated with lower levels of sexual risk-taking, while the jock identity was associated with higher levels of sexual risk-taking.

In sum, this body of research has highlighted the importance of crowd identities and participation in extracurricular activities as influences on problem behavior. This research, however, has several gaps. First, few studies assess crowd identities and activities simultaneously, allowing their joint influence to be compared. Second, many studies measure crowd identification and peer group activity in general ways in samples of students, rather than making reference to specific identities and activities among an entire school population. Finally, and critically for our purposes, prior studies have not used network analysis techniques to measure exactly which students influence which others through these identities and activities.

The goals of this study are both theoretical and methodological. The theoretical goal is to examine affiliation mechanisms of peer influence with respect to drinking behavior by separating adolescent affiliation through sharing crowd identification (cognitive affiliation) from affiliation through interacting with sport activities (active affiliation), then to determine how combining cognitive and active affiliations augment each other in this affiliation-based influence process. The methodological goal is to introduce a network analytic method that can separate influence of crowd identification (or cognitive affiliation) from the influence of peer group affiliation through extracurricular activities such as sports on behaviors such as drinking. Specifically, we aim to compare the impact of exposure to drinking linked to cognitive affiliation with the impact of exposure to drinking linked to peer group affiliation using an extension of the affiliation exposure model (Fujimoto et al., 2012).

This method allows us to determine whether a combination of cognitive and active affiliation has a greater impact on behavioral influence processes than either one alone. For example, a student may identify him or herself as a "jock," even though he or she does not participate in organized sports and a student may play sports but not identify as a "jock." However, a student may also cognitively identify with the "jock" crowd and actively affiliate with others who participate in sports.

The procedure for this study is as follows: First, we examine the main effects of both identification with crowd types and participation in organized sports activities on adolescent drinking behavior. Methodologically, we use the affiliation exposure model (Fujimoto et al., 2011; Fujimoto et al., 2012) to examine the impact of two levels of exposure to (1) drinkers with shared crowd identities, and (2) drinkers who jointly participated in organized sports activities, on adolescent drinking status. Second, we disentangle the influence processes through which adolescent identification with peer crowds overlaps with sports activity participation. We specify 
two forms of drinking influence through activity involvement: drinking influence from (2-a) activity members who share at least one crowd identification, and (2-b) activity members who do not share any crowd identifications. Methodologically, this study introduces a new application of the network approach for disentangling potential overlapping influences (Fujimoto, 2012; Fujimoto \& Valente, in press) that may impact adolescent drinking, by mixing information from two different types of affiliation networks. Finally, we explore how these exposure measures vary by drinking levels by conducting an ordinal regression analysis. We hypothesize that cognitive affiliation (shared crowd identification) in conjunction with active affiliation (shared sport participation) will have a stronger association on drinking than the independent measures alone.

We focus here on sports rather than on other non-sports activities such as clubs or organizations, because athletes have more risk-taking peers (Barber et al., 2005) and experience higher levels of peer pressure (Hansen et al., 2003) than non-athletes. Additionally, organized sports activities provide a forum in which a reputationbased collective can enhance its reputation or popularity by providing visibility to its members (Eder, 1985). Participating in sports serves as an opportunity for adolescents to express their crowd identity (Eccles et al., 2003), and an athletically oriented crowd identity is associated with high peer status (Brown \& Lohr, 1987). For example, the jock identity can be enacted through football, basketball, or other sports activities, influencing reputation and peer status, particularly among others who share the jock identity. In this sense, influence or peer pressure among those who share the jock identity is expected to be stronger than from those who do not share the jock identity.

\section{Data and methods}

\subsection{Sample}

This study was nested within a larger social network study investigating how social network data may be used to identify adolescents at risk for negative health behaviors such as alcohol use, smoking, or other drug use (Valente et al., in press). Data were collected among adolescents in five southern California (Los Angeles County) high schools in the El Monte Unified High School District (EMUHSD). EMUHSD is a predominately Hispanic/Latino district with $75 \%$ to $90 \%$ of students being eligible for free or reduced lunch. Additionally, approximately $60 \%$ of families in EMUHSD are first-generation immigrant families. US-born children of foreign-born parents have a higher prevalence of substance use relative to foreign-born children (Harris, 1999).

The data for this study come from a cross-sectional sample of 1,707 students interviewed in the five schools. We approached the school district superintendent and obtained support for the study. We followed up with principals and teachers from each school and asked permission to conduct paper and pencil surveys in the schools. All five high schools in the school district participated and students were interviewed in October 2010. Of the 2,290 10th grade students, 2,016 returned valid parental consent forms $(88.0 \%)$ with 1,823 agreeing to participate in the study. Some 28 of these did not provide student assent, reducing the eligible pool to 1,795 students of whom 1,707 completed surveys ( $74.5 \%$ overall participation rate). 
Students completed surveys during the regular school day during the English (for three schools) or History class (two schools) (Valente et al., in press).

To collect network data, respondents were provided a grade roster containing all the students' ID and photos and asked to write the roster IDs of up to seven close friends in the same grade. Additionally, the nomination question also permits respondents to name up 12 additional friends. This study includes all friendship nominations for a maximum of 19. Survey data also include substance use behavior including alcohol use, crowd self-identification, participation in organized schoolsponsored sports activities, and standard demographic information (e.g., gender, race, and socioeconomic status). To measure drinking stage, four key alcohol use behaviors were combined into an ordered categorical scale for the ordinal regression analysis.

\subsection{Measures}

\subsubsection{Outcome variables}

Four questionnaire items ${ }^{1}$ on adolescent alcohol use were combined to create a five-stage drinking measure: (1) "non-susceptible to drink" represents adolescents who neither drank nor intend to drink in the next year, (2) "susceptible to drink" represents current non-drinkers who refuse to disavow drinking in the next year, (3) "ever drink" represents adolescents who have ever drunk in their life, (4) "pastmonth drink" represents those who have drunk alcohol in the past 30 days, and (5) "binge drink" represents those who have had five or more drinks of alcohol in a row during the past 30 days. The same drinking variable was also used to compute the level of friends' drinking behavior and affiliation exposures based on crowd identification and organized sports activities.

\subsubsection{Drinking exposures through crowd identification and sports}

To compute the level of drinking exposure through crowds, we assessed crowd identification by asking respondents "Which group or groups would you say you belong to?" and providing a list of 22 crowd types ${ }^{2}$. We assessed adolescents participation in school-organized sports by asking respondents to "Mark all of the sports and teams at your school that you have participated in during the past 12 months (do not count PE)," and providing a list of 16 sports $^{3}$.

1 The first item asked "At any time in the next year (12 months), do you think you will drink alcohol?" and the response had four categories of "definitely not," "maybe no," "maybe yes," and "yes, definitely." The second item asked "During your life, on how many days have you had at least one drink of alcohol?" and the response consisted of seven categories, ranging from " 0 days" to "100 or more days." The third item asked "During the past 30 days, on how many days did you have at least one drink of alcohol?" and the response consisted of seven categories, ranging from "0 days" to "all 30 days." The last item asked "During the past 30 days, on how many days did you have five or more drinks of alcohol in a row, that is, within a couple of hours?" and the response consisted of seven categories, ranging from "0 days" to "20 or more days."

2 These crowd types include artistic kids, athletes, ballers, emo, gamers, gangsters, geeks, goths, hipsters, jocks, LGBT students, musicians, nerds, Paisas, popular kids, punks, recently immigrated kids, regular kids, rockers, skaters, smart kids, and stoners/druggies.

3 These sports are basketball, baseball, cheerleading, cross country, dancing, exercising, field hockey, football, hiking, soccer, softball, swimming, tennis, running, volleyball, and wrestling. 
Exposure to drinking through active sports affiliation accounted for (i) the number of sports all pairs of adolescents jointly participated in, and (ii) the total number of sports each adolescent participated in. For joint participation (i), we used the affiliation exposure model (Fujimoto et al., 2011; Fujimoto et al., 2012) which measures the extent to which an adolescent is exposed to drinkers via jointly participating in sport activities. It is computed based on affiliation matrices, $A$, for each school in which the rows indexed adolescents, and the columns indexed the 16 sport activities. These affiliation matrices were then multiplied by their transposes $\left(A_{i j} A_{i j}^{\prime}\right)$ to generate a one-mode actor-by-actor co-participation matrix, $C_{i j}$, where each off-diagonal entry represents the number of activities each pair of adolescents jointly participated in. The co-participation matrix, $C_{i j}$, was then row-normalized by dividing each entry by the row total of the $C_{i j}$ matrix $\left(\sum_{j} C_{i j}\right)$ to ensure that the entry values range from 0 to 1 , but we suppress the diagonal entries by setting them to be zero. Finally, we multiplied the normalized co-participation matrix, $C_{i j}$, by the vector of drinking stages for each alter $\left(Y_{j}\right)$. The resulting vector of affiliation exposure values $\left(F_{i}\right)$ represents the average drinking stage of the adolescents with whom they jointly participated in sports with (ranging from 0 to 5), weighted by the proportion of all sports each pair of adolescents participated in. The general formula of the affiliation exposure model is defined as follows (Fujimoto, et al., 2012):

$$
F_{i}=\frac{\sum_{j} C_{i j} Y_{j}}{\sum_{j} C_{i j}} \quad \text { for } \quad i, j=1, \ldots, N, i \neq j
$$

where $F_{i}$ is the affiliation exposure for actor $i, C_{i j}$ is the co-participation matrix, and $Y_{j}$ is the vector of alter $j$ 's behavioral attribute $(j=1, \ldots, N ; j \neq i)$. For estimating the effects of participation alone (ii), we included the total number of sports a respondent participated in (i.e., diagonal entries of the co-participation matrix, $C_{i j}$, where $i=j$ ), as a control variable. We computed the equivalent measures for drinking exposure through crowd identities.

To address potential confounding of shared crowd identification with joint sports participation, a "decomposed affiliation exposure model" that integrates both into the computation of drinking exposure was computed (Fujimoto, 2012). This model calculates drinking exposures for (2-a) activity members who shared at least one crowd identification, and for (2-b) activity members who did not share any crowd identifications. Computation of these decomposed affiliation exposure models (2a and 2-b) using the combined co-identification and co-participation matrices is defined as:

$$
\begin{aligned}
& D_{i,(2-a)}=\frac{\sum_{j}\left\{\operatorname{sgn}\left(C_{\mathrm{crowd}, i j}\right) C_{\text {sport }, i j}\right\} Y_{j}}{\sum_{j}\left\{\operatorname{sgn}\left(C_{\mathrm{crowd}, i j}\right) C_{\mathrm{sport}, i j}\right\}} \text { for } i, j=1, \ldots, N, i \neq j, \\
& D_{i,(2-b)}=\frac{\sum_{j}\left\{\left[1-\operatorname{sgn}\left(C_{\mathrm{crowd}, i j}\right)\right] C_{\mathrm{sport}, i j}\right\} Y_{j}}{\sum_{j}\left\{\left[1-\operatorname{sgn}\left(C_{\mathrm{crowd}, i j}\right)\right] C_{\mathrm{sport}, i j}\right\}} \text { for } i, j=1, \ldots, N, i \neq j,
\end{aligned}
$$

where $D_{i,(2-a)}$ and $D_{i,(2-b)}$ are the decomposed affiliation exposures for (2-a) and (2-b) respectively for actor $i, C_{\text {crowd }, i j}$ is the co-identification matrix, $C_{\text {sport }, i j}$ is the 
co-participation matrix, and $Y_{j}$ is the vector of alter $j$ 's behavioral attribute $(j=$ $1, \ldots, N ; j \neq i$ ). Mathematically, (2-a) was computed by calculating the element-wise product of the co-participation matrix, $C_{\mathrm{sport}, i j}$, by the binarized co-identification matrix, $\operatorname{sgn}\left(C_{\text {crowd }, i j}\right)$ (representing at least one crowd identities shared with alters) and then row-normalized and matrix-multiplied by the vector of drinking stages of alters $\left(Y_{j}\right)$. To compute (2-b), we subtracted the binarized co-identification matrix, $\operatorname{sgn}\left(C_{\text {crowd }, i j}\right)$, from a square matrix with all off-diagonal elements 1 , and everything else being identical to the computation of (2-a).

\subsubsection{Other control variables}

This study controlled for exposure to friends' drinking by linking friendship nominations to nominated friends' self-reported drinking via the network exposure model (Valente, 1995; Valente, 2005). Exposure to friends' drinking was measured as the average drinking stage in an ego's friends' network. Our study also controlled for demographic and socioeconomic features: age (in years), gender (female $=1$; male $=0$ ), ethnicity (Hispanics/Latino $=1$; others $=0$ ), self-reported academic grades (ranging from 1 for "mostly F's" to 4 for "mostly A's"), a dummy variable indicating whether respondents receive free lunch or not, the ratio of the number of rooms to the number of people in the household, and a dummy variable indicating parental drinking (at least one of them drinks alcohol at least once per week $=1$; otherwise $=0$ ) in the analysis. Additionally, we controlled for popularity measured by taking the square root of the indegree (i.e., the frequency being nominated as a friend), the total number of crowds identified with, the total number of sports participated in, and a dummy variable indicating any sport participation (about half of students did not participate in any sport). Finally, we included school dummy variables in the model. The distributions of the missing cases in the final sample (out of $\mathrm{N}=1,707)$ were $215(12.60 \%)$ for the drinking variable, $41(2.40 \%)$ for age, $59(3.44 \%)$ for gender, $56(3.28 \%)$ for race, $126(7.38 \%)$ for academic grades, $77(4.51 \%)$ for receiving free lunch, $128(7.50 \%)$ for the ratio of room to people in household, $258(15.11 \%)$ for parental drinking, and $407(23.84 \%)$ are missing at least one of these variables. Students who had at least one missing value were older, more likely to be Hispanic, and more likely to be students with lower grades.

\subsection{Statistical analyses}

Ordinal regression was used to model the association between drinking exposures and various stages of drinking. We assumed that crowd identification and activity affiliation form an additive model of influence on a logit scale. This study estimated four cumulative logit models to model cumulative probabilities of respective drinking stages based on the four dividing points in the ordinal dependent variable. The first equation models the log odds of susceptibility to drinking or any actual drinking (lifetime drinking, past-month drinking, and binge drinking) versus non-susceptible to drinking, the second equation models the log odds of any drinking (lifetime, past-month, and binge) versus non-drinking, and so on. We assume a "partial proportional odds" (Williams, 2006) where some but not all variables meet the 
proportional odds assumption that all covariates have the same effect on the odds as the response variable has at any dividing point of the drinking stages.

We first examined which covariates met the proportional odds assumption based on a series of Wald tests using all of the covariates and then constrained proportionality only for the variables that met this assumption (i.e., estimating a common odds ratio across four cumulative logit models with different cutpoints). We used the gologit 2 command (user-written program implemented in Stata) (Williams, 2006) to model four equations simultaneously. Additionally, this study imputed missing values (required for approximately $25 \%$ of our sample) by using switching regression, an iterative multivariable regression technique of multiple imputations $(\mathrm{M}=50)$ by chained equations (Royston, 2004). We first modeled each drinking stage as a function of the main effects of (1) drinking exposure through crowd identity, and (2) drinking exposure through sports activities, controlling for drinking exposure to friends and other variables. Then, we fit the second model with a decomposed version of (2), that is: (2-a) drinking exposure to members who shared at least one crowd identification, and (2-b) drinking exposure to members who did not share any crowd identification.

\section{Results}

Table 1 provides a description of the sample characteristics and descriptive statistics of the study variables $(\mathrm{N}=1,707)$.

The sample consisted of $31 \%$ being not susceptible to drinking, $4 \%$ being susceptible, $27 \%$ having "ever drunk," $11 \%$ having drunk in the past month, $14 \%$ having been a binge drinker at least once during the past month, and $12 \%$ missing. When converted to a five-point scale, the average score was 2.70. Additionally, $11 \%$ of students did not identify with any of the crowds, $46 \%$ of students did not participate in any sports, and $7 \%$ of students did neither.

\subsection{Ordinal logistic regression analysis}

Table 2 shows the results of the pooled estimates of the odds ratios from the imputed datasets on each drinking stage for: (1) drinking exposure through crowd identity, and (2) drinking exposure through sports activities with inclusion of drinking exposure to friends and other control variables (Model 1). A series of Wald tests indicated that the control variables of academic grades, ratio of room to people, parental drinking, and popularity did not meet the proportional odds assumption, so our models show un-constrained proportionality for these variables.

Drinking exposure through crowd identification had a significant effect on all stages of drinking (Adjusted Odds Ratios (AOR) $=1.24 ; \mathrm{p}<0.01$ ) as did exposure through sports participation $(\mathrm{AOR}=1.54 ; \mathrm{p}<0.05)$. These results indicate that shared identification with crowd types and joint participation in sports have individual and distinct main effects on adolescent drinking behavior regardless of dividing points of drinking stage. Results also showed that the total number of crowds had significant effects on any drinking stages $(\mathrm{AOR}=1.04 ; \mathrm{p}<0.05)$, but the total number of sports did not. This result indicates the number of crowds one identifies with was associated with drinking behavior. 
Table 1. Descriptive statistics of percentages or means with standard deviations, min, and max values for outcome, controlled variables, and exposure measures $(N=1,707)$.

\begin{tabular}{lc}
\hline \hline & $\begin{array}{c}\text { Percentages or mean } \\
(\text { SD; min, max) }\end{array}$ \\
\hline Drinking status & $31 \%$ \\
$\quad$ Non-susceptible to drinking & $4 \%$ \\
Susceptible to drinking & $27 \%$ \\
Ever drunk & $11 \%$ \\
Past-month drinking & $14 \%$ \\
Binge drinking & $2.70(1.47 ; 1,5)$ \\
Mean & $15.07(0.43 ; 14,18)$ \\
Age & $48 \%$ \\
Female & $74 \%$ \\
Hispanic/Latino & $2.60(0.93 ; 1,4)$ \\
Academic grade level & $82 \%$ \\
Receiving free lunch & $0.93(0.64 ; 0.17,6)$ \\
Ratio of room to people in a household & $41 \%$ \\
Parental drinking & $5.45(3.72 ; 0,23)$ \\
Popularity (square root of indegree) & $2.59(1.22 ; 0,5)$ \\
Drinking exposure to friends & $2.94(2.83 ; 0,22)$ \\
Total number of crowds identified & $1.18(1.64 ; 0,16)$ \\
Total number of sports participated in & \\
Affiliation exposures & $2.13(0.81 ; 0,3.72)$ \\
$\quad$ Drinking exposure through crowd identity & $1.30(1.22 ; 0,3.77)$ \\
Drinking exposure through sports activities & \\
Decomposed affiliation exposures & $1.21(1.25 ; 0,4.67)$ \\
$\quad$ (2-a) Drinking exposure through sports with shared identification \\
(2-b) Drinking exposure through sports without shared & $1.35(1.36 ; 0,5)$ \\
$\quad$ identification & \\
\hline \hline &
\end{tabular}

Note: Hispanic includes Central American, Chicano or Chicana, Hispanic, Latino or Latina, Mexican, Mexican-American, and South American.

As for the results of control variables, drinking exposure to friends had a significant effect on all stages of drinking $(A O R=1.18 ; \mathrm{p}<0.001)$. Additionally, older adolescents, females, and Hispanics/Latinos were more likely to drink. Furthermore, adolescents with drinking parents and more popular adolescents were more likely to drink, although the effect sizes decrease with increasing drinking stages (becoming no longer significant for past-month and binge drinking). On the other hand, adolescents with higher academic grades were less likely to drink, although these effect sizes also decreased with increasing drinking stages.

Table 2 also shows the results for decomposed drinking exposures to activity members who shared at least one crowd identity and those who did not. Model 2 reports the pooled estimates of odds ratios on each dividing point of drinking stage for (2-a) drinking exposure through sports with shared identifications, and (2-b) drinking exposure through sports without a shared identification. Models include drinking exposure to friends and other control variables. A series of Wald tests indicated that both (2-a) and (2-b), as well as the same control variables that violated proportional odds assumption in Model 1 did not meet the proportional 
Table 2. Estimated adjusted odds ratio of cumulative logit model with partial proportional odds assumption $(N=1,707)$.

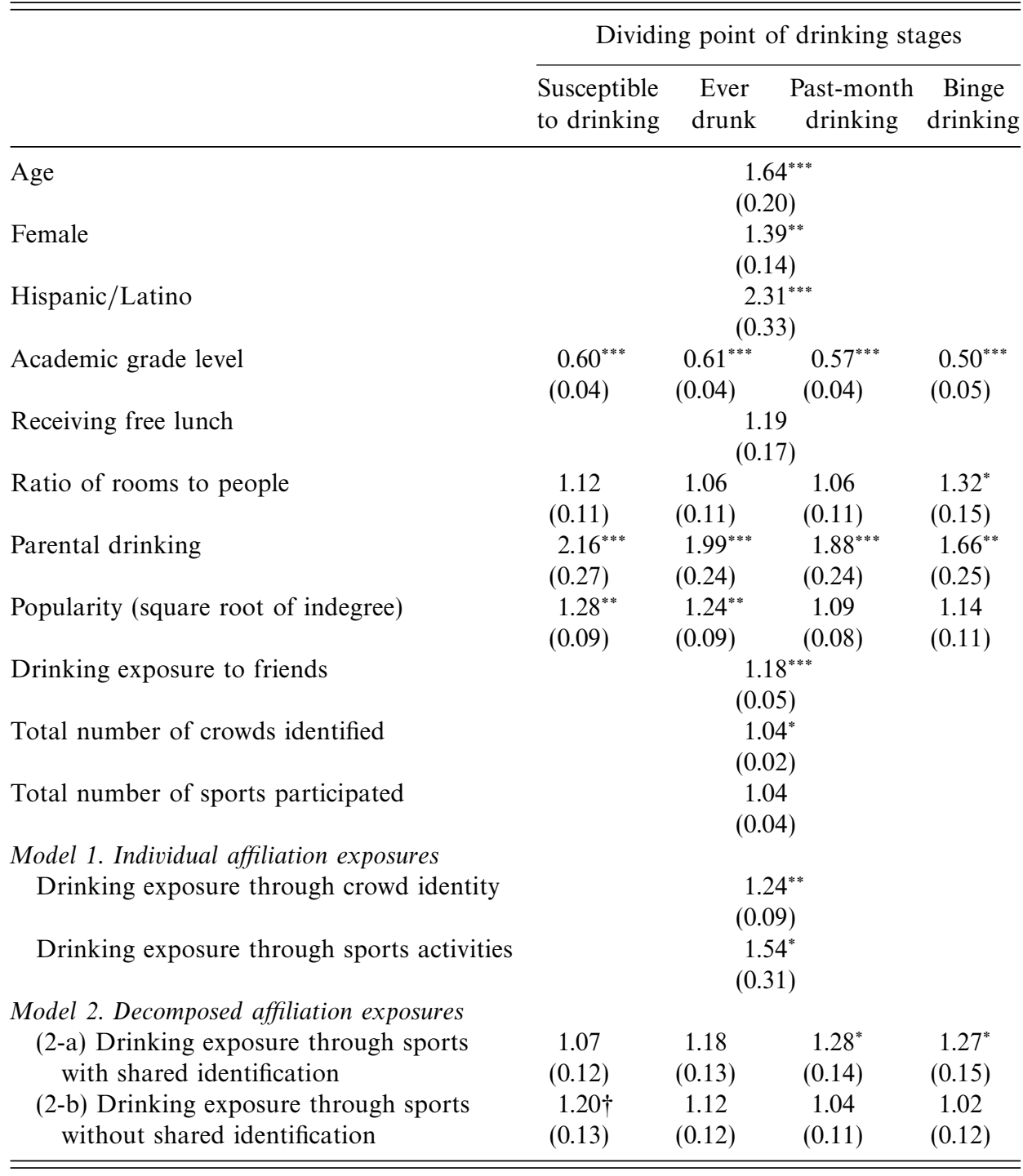

$\dagger \mathrm{p}<0.1 ;{ }^{*} \mathrm{p}<0.05 ;{ }^{* *} \mathrm{p}<0.01 ;{ }^{* * *} \mathrm{p}<0.001$ for two-tailed test. Numbers in parentheses represent standard errors. Reported adjusted odds ratio for controlled variables (i.e., age, female, Hispanic/Latino, academic level, receiving free lunch, ratio of room to people, parental drink, popularity, drinking exposure to friends, number of crowd identified with, and number of sports participated in) was estimated based on Model 1. Models control for school identifiers and dummy marker of activity participation.

odds assumption in Model 2, so our models show un-constrained proportionality on these variables.

Drinking exposure through sports with shared identifications had significant effects on past-month drinking or more $(\mathrm{AOR}=1.28$; $\mathrm{p}<0.05)$, and on binge drinking $(\mathrm{AOR}=1.27 ; \mathrm{p}<0.05)$, but not on being susceptible to drinking and lifetime drinking, which indicates that as adolescents were exposed to drinking by activity 
members with shared crowd identities, they were more likely to drink frequently. On the other hand, drinking exposure through sports without shared identification had a marginally significant effect only on the dividing point of being susceptible to drinking, with the odds of intending to drink in the next year or drinking, as opposed to not to intend to drink, being 1.20 ( $\mathrm{p}<0.1$ for two-tailed test). The direction of the association between drinking exposures through sports without shared identities was consistent at the other cut-off points.

\section{Discussion}

This is the first empirical study to examine shared crowd identities in relation to different stages of adolescent drinking behavior. Our results showed that shared crowd identification had a significant impact on all stages of drinking, controlling for the well-known friends' influence effect. This study also introduced a new application of the "decomposed affiliation exposure model" that assessed the degree to which adolescent crowd identities overlap with interactions derived from participating in sports activities. We demonstrated that joint participation in sports with members who share the same crowd identity had an impact on more frequent drinking (past-month, and binge drinking), while the effect of joint sports participation with members who do not share the same crowd identity had an impact only on intention to drink (no intention to drink vs. any other levels of drinking).

Theoretically, this study provides a framework for disentangling different sources of peer influence (crowds and sports) and how they overlap. The main methodological contribution of this study is to illustrate an extended capability of distinguishing two different but additive affiliation influence processes to the standard affiliation exposure model (Fujimoto et al., 2012). One advantage of our method of decomposing one type of affiliation network (crowd identification) based on the information of another type of affiliation network (sports participation) is that it can be extended to other types of networks, such as friendship networks, participation in after-school programs, teacher ratings, and so on. Previous studies have shown an interactive influence of best friends, peer groups, and crowd affiliation on smoking (SimonsMorton \& Farhat, 2010). Our network method enables one to decompose these overlapping influences to determine the conditions under which peer influence is most likely to occur.

Another advantage of this method is that it measures identity and activity influences derived from the behaviors of others in the school. So the influence mechanism is not the identification or activity per se, but rather the behavior of who else identifies with the crowd or participates in the sport. Future studies may uncover how various affiliations overlap and interact with one another beyond crowd identification and sports participation.

Our results are restricted by some limitations. First, this study did not address the role of perceived group norms which may mediate the relationship between group identity and substance use (Verkooijen et al., 2007). Future research might explore this and other mediators that influence adolescent substance use behavior. Second, although our study shifts attention from specific types of crowd identification to the shared nature of multiple crowd types, such multiple crowds may have opposing norms with regard to a specific behavior (such as substance use), and some qualitative 
research into how such "norm conflicts" (Verkooijen et al., 2007) are resolved would be enlightening. Third, our study assumed that organized sports are an area through which adolescents can execute their identities. However, peer crowd identification could also be influenced via sports participation. For instance, a youth who identifies as "average" may come to identify as a "jock" after a season on the football team. Fourth, our results were based on cross-sectional data, therefore are limited in their ability to understand the process of peer selection. It may be that adolescents identify their crowds based on their drinking status, or participate in sports to drink. Future longitudinal studies should be conducted to unravel the causal mechanism(s) by taking the selection processes into consideration in assessing affiliation-based peer influence. Furthermore, the sample was predominantly Hispanic adolescents with lower socioeconomic status (SES), and therefore our findings might be applicable only to this population.

Lastly, we used ordinal regressions which assume the observations are independent. This assumption is unrealistic when analyzing social network data. For example, friendships may depend on whether two people share similar crowd identifications or jointly participate in sports. In turn, the individuals' drinking behaviors are likely to be dependent on their network position. For example, drinking may be more common among students who share similar identifications or participate in common sports. Taking into account the dependent nature of the network data, we may apply exponential random graph models (ERGMs) to model the network structures (Frank \& Strauss, 1986; Robins et al., 2007; Wasserman \& Pattison, 1996) as well as autologistic actor attribute models (ALAAMs) (Daraganova \& Robins, 2013; Robins et al., 2001) for the drinking behavior. There are some recent development on ERGMs for affiliation networks and multiple networks (e.g., Agneessens \& Roose, 2008; Pattison \& Wasserman, 1999; Snijders et al., 2013; Wang et al, 2013a; Wang et al., 2013b; Wang, 2013). However, the currently available software implementations for ERGMs and ALAAMs (e.g., statnet (Handcock et al., 2003) and PNet (Wang et al., 2006)) are not able to capture the complexity of the data structure presented here which involves a one-mode friendship network, two affiliation networks, and various nodal attributes. Accommodating such complexity calls for future model developments on both ERGMs and ALAAMs, and we may be able to address the issue of interdependence of network data using ERGMs or ALAAMs in a subsequent paper.

Despite these limitations, this study offers an empirical investigation into the influence processes through which the adolescent identification with a crowd intersects with their sports activity participation. These findings may inform policy discussions surrounding school-based substance use prevention programs. These findings may also contribute to the design of more effective school-based substance use prevention programs (Valente, 2010). Current guidelines recommend the use of peer leaders to implement such programs, and numerous studies have conducted peer-led interventions using social network analysis where opinion leaders can accelerate the diffusion of positive attitudinal and behavioral changes (Audrey et al., 2008; Campbell et al., 2008; Valente, 2012). The effectiveness of such peer-led interactive programs (those that incorporate student-to-student exercises) would be enhanced if the programs are implemented in the context of school-sponsored organized activities with the knowledge of their crowd identification. Indeed, understanding that peer influences 
occur within the context of joint participation in activities with and without shared crowd identity provides an important distinction in how adolescents normalize substance use.

Organized sports serve as a place to execute adolescents' cognitive identification with specific crowds that influence their drinking behaviors, yet other members in peer groups still influence their normative beliefs about drinking and intentions. We believe that our study provides a way to tease apart these multiple embedded peer contexts in order to give us greater insight into tailoring substance use intervention programs according to each collection of unique and individual adolescents for improved outcomes.

\section{Acknowledgements}

This study was supported by NIH grant number 1RC1AA019239-01, 1K99AA 019699-01, and 4R00AA019699-03 from the National Institute on Alcohol Abuse and Alcoholism, and 1R01MH100021 from National Institute on Mental Health. We also thank the El Monte Union High School District for their assistance with this study. We also acknowledge Jennifer Unger, Daniel Soto, and Daniella Meeker as well as anonymous reviewers for providing us with comments on our earlier version of this paper. Finally, we thank Erik H. Lindsley for technical support.

\section{References}

Agneessens, F., \& Roose, H. (2008). Local structural patterns and attribute characteristics in 2-mode networks: $\mathrm{p}^{*}$ models to map choices of theatre events. Journal of Mathematical Sociology, 32, 204-237.

Audrey, S., Holliday, J., \& Campbell, R. (2008). Commitment and compatibility: Teachers' perspectives on the implementation of an effective school-based, peer-led smoking intervention. Health Education Journal, 67(2), 74-90.

Barber, B. L., Stone, M., Hunt, J., \& Eccles, J. S. (2005). Benefits of activity participation: The roles of identity affirmation and peer group norm sharing. In J. L. Mahoney, R. Larson, \& J. S. Eccles (Eds.), Organized activities as contexts of development: Extracurricular activities, after school and community programs (pp. 185-209). Mahwah, NJ: Lawrence Erlbaum Assoc Inc.

Brown, B. B. (1990). Peer groups and peer cultures. In S. S. Feldman, \& G. R. Elliott (Eds.), At the threshold: The developing adolescent (pp. 171-196). Cambridge, MA: Harvard University Press.

Brown, B. B., Eicher, S. A., \& Petrie, S. (1986). The importance of peer group ("crowd") affiliation in adolescence. Journal of Adolescence, 9(1), 73-96.

Brown, B. B., \& Lohr, M. J. (1987). Peer group affiliation and adolescent self-esteem: An integration of ego identity and symbolic interaction theories. Journal of Personality and Social Psychology, 52(1), 47-55.

Brown, B. B., Lohr, M. J., \& Trujillo, C. (1990). Multiple crowds and multiple life styles: Adolescents' perceptions of peer-group stereotypes. In R. E. Muuss (Ed.), Adolescent behavior and society (4th ed.) (pp. 30-36). New York: McGraw-Hill Publishing Company.

Campbell, R., Starkey, F., Holliday, J., Audrey, S., Bloor, M., Parry-Langdon, N.,... Moore, L. (2008). An informal school-based peer-led intervention for smoking prevention in adolescence (ASSIST): A cluster randomized trial. The Lancet, 371, 1595-1602.

Coleman, J. S. (1961). The adolescent society. New York: Free Press.

Coleman, J. C. (1974). Relationships in adolescence. London: Routledge \& Kegan Paul. 
Coleman, J. C. (1980). Friendship and peer group acceptance in adolescence. In J. Adelson (Ed.), Handbook of adolescent psychology (pp. 408-431). New York: John Wiley.

Costanzo, P. R., \& Shaw, M. E. (1966). Conformity as a function of age level. Child Development, 37, 967-975.

Daraganova, G., \& Robins, G. (2013). Autologistic actor attribute models. In D. Lusher, J. Koskinen, \& G. L. Robins (Eds.), Exponential random graph models for social networks: Theories, methods and applications. Cambridge, MA: Cambridge University Press.

Darling, N. (2005). Participation in extracurricular activities and adolescent adjustment: Cross-sectional and longitudinal findings. Journal of Youth and Adolescence, 34(5), 493-505.

Eccles, J. S., \& Barber, B. L. (1999). Student council, volunteering, basketball, or marching band: What kind of extracurricular involvement matters? Journal of Adolescent Research, 14(1), 10-43.

Eccles, J. S., Barber, B. L., Stone, M., \& Hunt, J. (2003). Extracurricular activities and adolescent development. Journal of Social Issues, 59(4), 865-889.

Eder, D. (1985). The cycle of popularity: Interpersonal relations among female adolescents. Sociology of Education, 58(3), 154-165.

Erikson, E. H. (1968). Identity, youth, and crisis. New York: Norton.

Frank, O., \& Strauss, D. (1986). Markov graphs. Journal of the American Statistical Association, 81, 832-842.

Fujimoto, K. (2012). Using mixed-mode networks to disentangle multiple sources of social influence. In S. J. Yang, A. M. Greenberg \& M. Endsley (Eds.), Social Computing, Behavioral-Cultural Modeling and Prediction, Lecture Notes in Computer Science, Vol. 7227 (pp. 214-221), Berlin/Heidelberg: Springer.

Fujimoto, K., Chou, C.-P., \& Valente, T. W. (2011). The network autocorrelation model using two-mode network data: Affiliation exposure and biasness in $\rho$. Social Networks, 33(3), 231-243.

Fujimoto, K., Unger, J., \& Valente, T. W. (2012). Network method of measuring affiliationbased peer influence: Assessing the influences on teammates smokers on adolescent smoking. Child Development, 83(2), 442-451.

Fujimoto, K. \& Valente, T. W. (in press). Alcohol peer influence from participating in organized school activities among U. S. adolescents: A network approach. Health Psychology. doi: 10.1037/a0029466

Gavin, L. A., \& Furman, W. (1989). Age differences in adolescents' perceptions of their peer groups. Developmental Psychology, 25(5), 827-834.

Handcock, M. S., Hunter, D. R., Butts, C. T., Goodreau, S. M., \& Morris, M. (2003). Statnet: Software tools for the statistical modeling of network data. Retrieved from http://statnetproject.org.

Hansen, D. M., Larson, R. W., \& Dworkin, J. B. (2003). What adolescents learn in organized youth activities: A survey of self-reported developmental experiences. Journal of Research on Adolescence, 13(1), 25-55.

Harris, K. M. (1999). The health status and risk behavior of adolescents in immigrant families. In D. Hernandez (Ed.), Children of immigrants: Health, adjustment, and public assistance (pp. 286-347). Washington, DC: National Academy Press.

Jessor, R. (1984). Adolescent development and behavioral health. In J. D. Matarazzo, S. M. Weiss, J. A. Herd, N. E. Miller, \& S. M. Weiss (Eds.), Behavioral health: A handbook of health enhancement and disease prevention. New York: John Wiley and Sons.

La Greca, A. M., Prinstein, M. J., \& Fetter, M. D. (2001). Adolescent peer crowd affiliation: Linkages with health risk behaviors and close friendships. Journal of Pediatric Psychology of Addictive Behaviors, 26(3), 131-143.

Mahoney, J. L. (2000). School extracurricular activity participation as a moderator in the development of antisocial patterns. Child Development, 71(2), 502-516. 
Mahoney, J. L., \& Cairns, R. B. (1997). Do extracurricular activities protect against early school dropout? Developmental Psychology, 33(2), 241-253.

Melnick, M. J., Miller, K. E., Sabo, D. F., Farrell, M. P., \& Barnes, G. M. (2001). Tobacco use among high school athletes and nonathletes: Results of the 1997 Youth Risk Behavior Survey. Adolescence, 36(144), 727-747.

Miller, K. E., Farrell, M. P., Barnes, G. M., Melnick, M. J., \& Sabo, D. (2005). Gender/racial differences in jock identity, dating, and adolescent sexual risk. Journal of Youth and Adolescence, 34(2), 123-136.

Miller, K. E., Hoffman, J. H., Barnes, G. M., \& Farrell, M. P. (2003). Jocks, gender, race, and adolescent problem drinking. Journal of Drug Education, 33(4), 445-462.

Mosbach, P., \& Leventhal, H. (1988). Peer group identification and smoking: Implications for intervention. Journal of Abnormal Psychology, 97(2), 238-245.

Newman, P. R., \& Newman, B. M. (1976). Early adolescence and its conflict: Group identity versus alienation. Adolescence, 11, 261-274.

Pate, R. R., Trost, S. G., Levin, S., \& Dowda, M. (2000). Sports participation and healthrelated behaviors among US youth. Archives of Pediatrics and Adolescent Medicine, 154(9), 904-911.

Pattison, P., \& Wasserman, S. (1999). Logit models and logistic regressions for social networks, II. Multivariate relationships. British Journal of Mathematical and Statistical Psychology, 52, 169-193.

Robins, G. L., Pattison, P., \& Elliott, P. (2001). Network models for social influence processes. Psychometrika, 66, 161-190.

Robins, G. L., Pattison, P., Kalish, Y., \& Lusher, D. (2007). An introduction to exponential random graph $\left(\mathrm{p}^{*}\right)$ models for social networks. Social Networks, 29, 173-191.

Royston, P. (2004). Multiple imputation of missing values. Stata Journal, 4(3), 227-241.

Simons-Morton, B. G., \& Farhat, T. (2010). Recent findings on peer group influences on adolescent smoking. Journal of Primary Prevention, 31, 191-208.

Snijders, T. A. B., Lomi, A., \& Torló, V. J. (2013). A model for the multiplex dynamics of twomode and one-mode networks, with an application to employment preference, friendship, and advice. Social Networks, 35, 265-276.

Sussman, S., Dent, C. W., \& McCullar, W. J. (2000). Group self-identification as a prospective predictor of drug use and violence in high-risk youth. Psychology of Addictive Behaviors, 14(2), 192-196.

Sussman, S., Pokhrel, P., Ashmore, R. D., \& Brown, B. B. (2007). Adolescent peer group identification and characteristics: A review of the literature. Addictive Behavior, 32(8), $1602-1627$.

Sussman, S., Simon, T. R., Stacy, A. W., Dent, C. W., Ritt, A., Kipke, M. D., ... Flay, B. R. (1999). The association of group self-identification and adolescent drug use in three samples varying in risk. Journal of Applied Social Psychology, 29(8), 1555-1581.

Sussman, S., Unger, J. B., \& Dent, C. W. (2004). Peer group self-identification among alternative high school youth: A predictor of their psychosocial functioning five years later. International Journal of Clinical and Health Psychology, 41(1), 9-25.

Valente, T. W. (1995). Network models of the diffusion of innovations. Cresskill, NJ: Hampton Press.

Valente, T. W. (2005). Network models and methods for studying the diffusion of innovations. In P. J. Carrington, J. Scott, \& S. Wasserman (Eds.), Models and methods in social network analysis: Structural analysis in the social sciences (pp. 98-116). Cambridge, MA: Cambridge University Press.

Valente, T. W. (2010). Social networks and health: Models, methods, and applications. New York: Oxford University Press.

Valente, T. W. (2012). Network interventions. Science, 337(6), 49-53. 
Valente, T. W., Fujimoto, K., Unger, J. B., Soto, D., \& Meeker, D. (in press). Variations in network boundary and type: A study of adolescent peer influences. Social Networks. doi: 10.1016/j.socnet.2013.02.008

Verkooijen, K. T., de Vries, N. K., \& Nielsen, G. A. (2007). Youth crowds and substance use: The impact of perceived group norm and multiple group identification. Psychology of Addictive Behaviors, 21(1), 55-61.

Wang, P. (2013). ERGM extensions: Models for multiple networks and bipartite networks. In D. Lusher, J. Koskinen, \& G. L. Robins (Eds.), Exponential random graph models for social networks: Theories, methods and applications. New York: Cambridge University Press.

Wang, P., Pattison, P. E., \& Robins, G. L. (2013a). Exponential random graph model specifications for bipartite networks - A dependence hierarchy. Social Networks, 35(2), 211-222.

Wang, P., Robins, G. L., \& Pattison, P. E., 2006. PNet: A program for simulations and estimations of exponential random graph models., Australia: Melbourne School of Psychological Sciences, The University of Melbourne. URL: http://sna.unimelb.edu.au/PNet.

Wang, P., Robins, G. L., Pattison, P. E., \& Lazega, E. (2013b). Exponential random graph models for multilevel networks. Social Networks, 35(1), 96-115.

Wasserman, S., \& Pattison, P. E. (1996). Logit models and logistic regression for social networks, I. An introduction to Markov graphs and p*. Psychometrika, 6(3), 401-425.

Williams, R. (2006). Generalized ordered logit/partial proportional odds models for ordinal dependent variables. The Stata Journal, 6(1), 58-82.

Wichstrøm, T., \& Wichstrøm, L. (2009). Does sports participation during adolescence prevent later alcohol, tobacco and cannabis use? Addiction, 104(1), 138-149. 